\title{
Sustainability or Collapse: What Can We Learn from Integrating the History of Humans and the Rest of Nature?
}

\begin{abstract}
Understanding the history of how humans have interacted with the rest of nature can help clarify the options for managing our increasingly interconnected global system. Simple, deterministic relationships between environmental stress and social change are inadequate. Extreme drought, for instance, triggered both social collapse and ingenious management of water through irrigation. Human responses to change, in turn, feed into climate and ecological systems, producing a complex web of multidirectional connections in time and space. Integrated records of the co-evolving human-environment system over millennia are needed to provide a basis for a deeper understanding of the present and for forecasting the future. This requires the major task of assembling and integrating regional and global historical, archaeological, and paleoenvironmental records. Humans cannot predict the future. But, if we can adequately understand the past, we can use that understanding to influence our decisions and to create a better, more sustainable and desirable future.
\end{abstract}

\section{INTRODUCTION}

What is the most critical problem facing humanity at the beginning of the 21 st century? Global pandemics, including acquired immunodeficiency syndrome? Global warming? Regional water shortages? Meeting global energy demands? Worldwide financial collapse? International terrorism? The answer is all of these and more. We live in a global system in which our most critical problems go well beyond regional and national borders. When past civilizations were challenged, or even collapsed, they were relatively isolated from other parts of the world. Today, in our highly interconnected global system, massive social or environmental failure in one region threatens the entire system. Perhaps the overarching question for the 21st century is the following: can the current global system adapt and survive the accumulating, highly interconnected problems it now faces?

Increasingly, the global environmental change community is realizing that answers to this question require a new, more integrated, transdisciplinary understanding of how humans have interacted with the rest of nature in the past. Our phrasing of the previous sentence is quite deliberate: "humans and the rest of nature" implies that humans are a part of nature, not separate from it. We emphasize "history" because much discussion of human-environment interactions continues to lack a long-term, temporal dimension. We need to learn from the past. For example, a full understanding of the modern condition requires knowledge of the evolution of the roles of technology, population expansions, cultural mores, climate, disease, and warfare in changing human attitudes, and responses through time. This is especially the case if the past is to be used in more sophisticated ways than as a simplistic analog of projected future conditions. We also know that assessment of the sensitivity or the vulnerability of modern landscapes and ecosystems to future human activities and climate can be greatly improved by knowing the rates and directions of past trajectories in key processes, such as land cover, soil erosion, and flooding; observing how thresholds have been transgressed; and deducing the natural or pre-impact patterns of environmental variability. Already, such knowledge is leading to the improved formulation of resource management strategies. Linked to this, it is clear that the past provides the means to test the models upon which we depend for future projections and scenarios: for climate, key ecological processes, changing socioenvironmental conditions, and the intensity of impacts. Such dependence demands sophisticated and creative testing of model outputs against what we already know in terms of the full range of data from historical narratives to quantitative time series. This is especially important where numerical models are attempting to capture nonlinear behavior in complex socioecological systems, like "adaptive cycles" and "tipping points."

The present nature and complexity of socioecological systems are heavily contingent on the past; we cannot fully appreciate the present condition without going back decades, centuries, or even millennia. Because we are witnessing today, with global warming, that current societal actions may reverberate in climatic and many other ways for centuries into the future. As such, there is the real danger that our visions of the future are becoming unconstrained by knowledge of what has already occurred, at least in part because information about human-environment interactions in the historical past has not been well organized for this purpose or properly used. If we continue to operate in ignorance or denial of this integrated historical understanding, we run the very real risk of mirroring the paths of the Easter Islanders, the Classic Maya, or the Roman Empire. But if we can adequately learn from our integrated history, we can create a sustainable and desirable future for our species.

\section{INTEGRATING HUMAN AND NATURAL HISTORY}

Human history has traditionally been cast in terms of the rise and fall of great civilizations, wars, specific human achievements, and extreme natural disasters (e.g., earthquakes, floods, plagues). However, this history tends to leave out the important ecological and climatic context and the less obvious interactions that shaped and mediated these events (Fig. 1). The capability to integrate human history with new data about the natural history of the Earth at global scales and over centuries to millennia has only recently become possible. This integrated history could not have been accomplished even 10 years ago and is a critical missing link that is needed to provide a much richer picture of how (and why) the planet has changed in historical times. Such an integrated history will advance research from various perspectives of the Earth's history and possible futures, 
and can be used as a critical shared data set to test integrated models of humans in natural systems.

Socioecological systems are intimately linked in ways that we are only beginning to appreciate (1-11). Furthering the research agenda on such systems poses great methodological challenges. Events can be selectively chosen from the past to support almost any theory of historical causation. Although Figure 1 puts a range of environmental indicators and historical events together on the same graph, it can show only coincidence, not causation. The causal links are more complex and not self-evident. For example, water availability is related to complex developments that result from social organization, engineering, and climate (see the Roman Empire period on Fig. 1). Although we use the time line to illustrate the parallels between human and environmental change, the complex web of causation that resulted in the sequence of events depicted cannot be easily represented on such a graph.

One major challenge in linking human and environmental change is the development of a new integrated analytical modeling paradigm that reveals the complex web of causation across multiple spatial and temporal scales, while allowing important emergent properties and generalities to rise above the details. Only with such a paradigm can we survey the past and test alternate explanations rigorously. To develop this integrated understanding, a project of the global change research community has been initiated titled "Integrated History and future of People On Earth (IHOPE)” (12).

\section{LONG-TERM GOALS OF THE IHOPE PROJECT}

The IHOPE project has three long-term goals:

i) Map the integrated record of biophysical and human system change on the Earth over the last several thousand millennia, with higher temporal and spatial resolution in the last 1000 and the last 100 years.

ii) Understand the socioecological dynamics of human history by testing human-environment system models against the integrated history.

iii) Based on these historical insights, develop credible options for the future of humanity.

To achieve the ambitious goals of IHOPE, multiple scientific challenges must be met. These include linking disparate disciplinary approaches, cultures, and models across the sciences and humanities; developing an appropriate information infrastructure to link such disparate information; and developing a common understanding and approach.

\section{EVOLUTION OF THE HUMAN-ENVIRONMENT RELATIONSHIP}

Human societies respond to environmental (e.g., climate) signals through multiple pathways, including collapse or failure, migration, and creative invention through discovery. Extreme drought, for instance, has triggered both social collapse and ingenious management of water through irrigation. Human responses to change may in turn alter feedbacks between climate, ecological, and social systems, producing a complex web of multidirectional connections in time and space. Ensuring appropriate future responses and feedbacks within the humanenvironment system will depend on our understanding of this past web and how to adapt to future surprises. To develop that understanding, we need to look at multiple time and space scales $(8-11)$.

At millennial time scales, different cultural elements (social and political structure, traditional practices, and beliefs, to name a few) enable or constrain responses. Even global-scale events (climate change, major volcanic activity, etc.) do not affect all regions at precisely the same time or with the same intensity. Models (conceptual and computational) of how societal characteristics and environmental conditions affect the resilience of socioecological systems are needed. Processes important for the study of resilience, vulnerability, or sustainability include the following: the degree of rigidity of social, economic, and political networks; the diversity of biophysical resources and of human resourcefulness; the development of complexity, costliness, and ineffectiveness in problem solving; and the cyclical expansion/contraction and geographical shift in the center of accumulation, with periodic declines and "dark ages" when external limits to social reproduction are reached. Simple, deterministic relationships between environmental stress (e.g., a climatic event) and social change are inadequate. Organizational, technological, and perceptual mechanisms mediate the responses of societies to environmental stress, and there are also time delays to societal responses.

More recent changes in the human-environment relationship, such as accelerated globalization and global environmental change, have deep roots in humanity's relationship with nature over the past millennium. Although we often associate the term "global change" with the greenhouse gas warming evident in the last decade, socioecological changes at continental and global scales were put in motion over at least the past 1000 years (e.g., many European landscapes looked much like they do today far earlier than this). Important phenomena include a rise in human population; the strengthening of nation states; the global transfer of inventions and values; the beginning of industrialization and the rise of global communications; and, associated with these, the dramatic modifications of land use and biodiversity, hydrological and energy flows, and key ecological processes.

The last 1000-year period is also interesting because it is a period when broad swings in temperature, as well as clusters of extreme weather events arguably changed the trajectory of history. The 14th century in Europe saw the end of the Medieval Warm Period. Particularly during the period from 1315-1317, Western Europe witnessed a combination of rainy autumns, cold springs, and wet summers that led to crop failures and a dramatic slowdown in urban expansion. These early Europeans were further subjected to the last major locust invasion (1338), the "millennium flood" (1342), and the coldest summer of the millennium in 1347. From 1347 to 1350 the "Black Death" devastated populations. The clustering of extreme events in the 14 th century fundamentally undermined the social order and was a key factor in a major wave of anti-Semitic pogroms and systematic discrimination. In the same period, agricultural land was abandoned and forests increased. Many would argue that it also led to the end of the feudal system; improved land and employee rights; and, through the enlightenment period, paved the way for the modern age. The Little Ice Age affected food availability in many parts of Europe, leading to the development of technological, economic, and political strategies as ways to reduce vulnerability. The exceptional 1788-1795 El Niño-Southern Oscillation event reverberated around the world in places as far afield as the first British colonial settlement in Australia, the Indian monsoon region, Mexico, and western Europe (13). Thus, the present nature and complexity of socioecological systems are heavily contingent on the past; we cannot fully understand the present condition without going back centuries or even millennia into the past. An important implication is that societal actions today will reverberate for centuries into the future in climatic and many other ways.

Turning to the more recent past, the 20th century witnessed several sharp changes in the evolution of socioecological systems, at both global (two world wars and the Great 
Temperature Anomaly $\left({ }^{\circ} \mathrm{C}\right)$ Human Population (billions) GWP index $(1960=1)$ Fraction land

(x10) Water Withdrawls (1000km3) CO2 (d260ppm/20) Methane (d400ppb/180) SE Asian Monsoon (-d180+5)

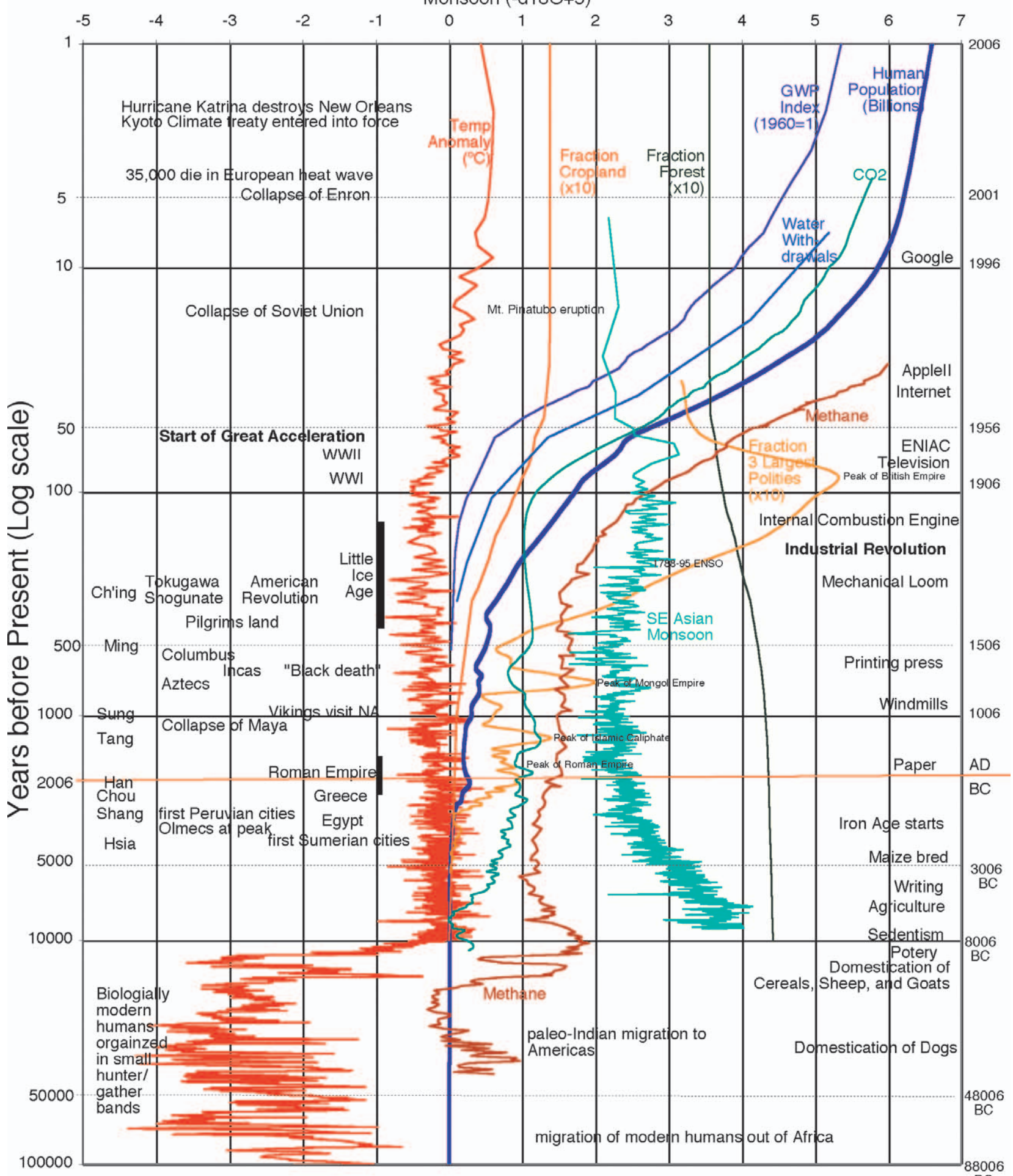

$\mathrm{BC}$

Figure 1. Selected indicators of environmental and human history. Although this depiction of past events is integrative and suggestive of major patterns and developments in the human-environment interaction, it plots only coincidence, not causation, and must, of course, be supplemented with integrated models and narratives of causation. In this graph, time is plotted on the vertical axis on a log scale running from 100000 years before present (BP) until now. Technological events are listed on the right side, and cultural/political events are listed on the left. Biologically modern humans arose at least 100000 years BP and probably more than 200 000-250 000 years BP, but sedentism (and later agriculture) did not start until after the end of the last ice age and the dramatic warming and stabilization of climate that occurred around 10000 years BP, at the Pleistocene/Holocene boundary. Northern Hemisphere temperature can be reconstructed for this entire period from ice core data, combined with the instrument record from 1850 until the present. Human population fluctuated globally at around 1 million until the advent of agriculture, after which it began to increase exponentially (with some declines as during the black death in Europe) to a current population of over 6 thousand million. Gross World Product (GWP) followed with some lag as people tapped new energy sources, such as wind and eventually fossil fuels. Atmospheric $\mathrm{CO}_{2}$ and methane closely track population, GWP, and energy use for the last 150 years. The start of the "Great Acceleration" after World War II can be clearly seen in the GWP, population, and water withdrawal plots. The plot for "SE Asian Monsoons" shows the long-term variability in this important regional precipitation pattern. Patterns in land use are shown as the fraction of land in forest, cropland, and in the "three largest polities." This area in large "polities" or sovereign political entities has increased over time, with significant peaks at the height of the Roman, Islamic Caliphate, Mongol, and British empires. Currently, the three largest polities are Russia, Canada, and China, together covering about $32 \%$ of the land surface. At the peak of the British empire in 1925, the three largest were Britain, Russia, and France, together covering about $53 \%$ of the land surface before the independence of British and French colonies. 
Depression) and regional (e.g., the failure of Soviet farming, its reliance on grain from the United States, and subsequent collapse as a polity) discontinuities. Variations in the growth rate of $\mathrm{CO}_{2}$ in the atmosphere occurred in response to both climatic controls over land-atmosphere-ocean fluxes (for example, $\mathrm{CO}_{2}$ increases more rapidly in El Niño years because of climate effects on terrestrial ecosystems) and political events (the growth rate slowed during the 1970s oil shock and after the breakup of the Soviet Union because of changes in fossil fuel use). The 20th century also marks the first period for which instrumental records of many environmental parameters have become available and for which detailed statistical records of many human activities have also been collected.

The most remarkable phenomenon on Earth in the 20th century was the "Great Acceleration," the sharp increase in human population, economic activity, resource use, transport, communication, and knowledge-science-technology that was triggered in many parts of the world (North America, Western Europe, Japan, and Australia/New Zealand) after World War II and which continued into this century (Fig. 1) (14, 15). Other parts of the world, especially the monsoon Asia region, are now also in the midst of the Great Acceleration. The tension between the modern nation-state and the emergence of multinational corporations and international political institutions is a strong feature of the changing human-environmental relationship. The "engine" of the Great Acceleration is an interlinked system that consists of population increase, rising consumption, abundant cheap energy, and liberalizing political economies.

Globalization, especially an exploding knowledge base and rapidly expanding connectivity and information flow, thus acts as a strong accelerator of the system. The environmental effects of the Great Acceleration are clearly visible at the global scale: changing atmospheric chemistry and climate, degrading many ecosystem services (e.g., provision of freshwater, biological diversity), and homogenizing the biotic fabric of the planet. The Great Acceleration is arguably the most profound and rapid shift in the human-environment relationship that the Earth has experienced.

Toward the end of the 20th century, there were signs that the Great Acceleration could not continue in its present form without increasing the risk of crossing major thresholds and triggering abrupt changes worldwide. Transitions to new energy systems will be required. There is a growing disparity between the wealthy and the poor, and, through modern communication, a growing awareness by the poor of this gap, leading to heightened material aspirations globally, a potentially explosive situation. Many of the ecosystem services upon which human well-being depends are depleted or degrading, with possible rapid changes when thresholds are crossed. The climate may be more sensitive to increases in $\mathrm{CO}_{2}$ and may have more inertia than earlier thought, raising concerns of abrupt and irreversible changes in the planetary environment as a whole.

From the past, we know that there are circumstances in which a society is resilient to perturbations (e.g., climate change), and there are circumstances in which a society is so vulnerable to perturbations that it will be unable to cope $(1,5)$. For example, Diamond (5) identifies what he considered to be the 12 most serious environmental problems facing past and future societies, problems that often have led to the collapse of historical societies:

i) Loss of habitat and ecosystem services,

ii) Overfishing,

iii) Loss of biodiversity,

iv) Soil erosion and degradation,

v) Energy limits, vi) Freshwater limits,

vii) Photosynthetic capacity limits,

viii) Toxic chemicals,

ix) Alien species introductions,

$x)$ Climate change,

xi) Population growth, and

xii) Human consumption levels.

More importantly, Diamond, and several other authors before him (16-20) emphasized that the interplay of multiple factors is almost always more critical than any single factor. Societies on the edge become brittle and lose resilience (including the ability to adapt social values to new circumstances), making them more susceptible to the impacts of potential perturbations of several kinds, including climate change, political corruption, war, and terrorism. In addition, what happens to any society is an emergent phenomenon, the result of individual decisions and conflicts in combination with environmental factors.

To make further progress, we need to construct a framework to help us understand the full range of human-environment interactions and how they affect societal development and resilience. We now have the capacity to develop this framework in the form of more comprehensive integrated models, combining approaches from geophysical, systems dynamics, and agent-based models to implement approaches, including simulation games and scenario analysis (21-23). Insights from modeling and analysis of the rich array of well-documented integrated historic events can be used to structure, test, and further develop these models.

A few examples of integrated dynamic historical simulation models now exist, including Turchin's work on historical dynamics (24), with several case studies on everything from the rise and fall of religions to imperial expansion and dynastic cycles, and agent-based simulation models of the growth and decline of the Anasazi in the southwestern United States (25). But the field is only beginning to mature, and we are poised to develop significantly better integrated dynamic simulation models to address the questions that IHOPE raises (26).

The fundamental question we need to ask is: how does the history of human-environment systems generate useful insights about the future? In trying to gain insights from the past, tests of alternate models must play a central role. Although in the natural sciences, alternate models can be tested against numerical data sets, in testing models (conceptual and computational) of the human-environment system, we need to use the full range of data from numerical time series to historical narratives. We also need to develop new skills and techniques for integrating these disparate data sources of fundamentally different characters. The extent to which we can (or cannot) reproduce historical behavior in socioecological systems determines the confidence we can place in future projections. An array of different modeling approaches, some focused strongly on the biophysical aspects of the Earth System (e.g., General Circulation Models of climate) and others centered on socioeconomic aspects (e.g., models of the global economy) have been developed for projecting Earth System behavior into the future. Integrated models at multiple spatial and temporal scales have also been developed (21-23). Recognizing that no single approach has intrinsic advantages, a strategy of comparing, synthesizing, and integrating the results from different modeling approaches is probably more productive, paralleling the use of multiple working hypotheses. Developing an integrated historical narrative and database will allow testing of alternate models, more rapid evolution of paradigms, and better answers to IHOPE-related questions. 


\section{RESEARCH CHALLENGES}

To address these issues, there are a set of research challenges that will need to be met regardless of the time scale or particular aspect of interest. These include:

i) Data on the behavior of socioecological systems vary enormously in quality, selection, interpretation, resolution, dating/chronologies, and evenness (27). The amount of data rises dramatically as we approach the present, and this could easily distort analyses.

ii) There is an issue regarding the balance, quality, and timing between social and environmental data. This makes it more difficult to explore the types or characteristics of environmental variability or change to which various societies are especially vulnerable.

iii) There can be differences in research approaches (i.e., reductionist vs. whole systems oriented) that can lead to tension within research teams and thus pose major challenges to interdisciplinary research projects. Studies need to adopt a range of alternative explanatory frameworks, embracing conventional scientific positivist approaches, as well as discipline-specific protocols. However, a key issue is the evaluation of explanations and the realistic appreciation of uncertainty. How we learn from the past takes different forms (28): the type and range of data sources, the different disciplinary conventions and the nature of conceptual and predictive models used imply that there is no single method to determine the quality and certainty of explanations. In some contexts, it may be possible to use a hypothesis-testing approach, but, in others, the ability to falsify hypotheses may be severely restricted. In many historical studies, the use of approaches that argue from the perspective of mutual internal consistency or weight of evidence may be more appropriate.

iv) In analyzing socioecological systems or simulating their behavior into the future, biophysical laws that govern aspects of nature can give an "envelope of regularities" in projections or analyses (but complex natural systems also have strong nonlinearities). This broad envelope of regularities can define the "environmental space" within which human societies operate, but contingent events, which may be difficult or impossible to predict, often determine the trajectories of socioecological systems within that space and are thus crucially important to how the future will actually unfold. As we continue to create the future, we need to know more about the range of possibilities.

v) Comprehensive models of the Integrated Earth System (or humans-in-nature) are still in their infancy and have a long way to go (22). Nearly all models begin with a strong emphasis on either the natural or the human part of socioecological systems. There is a need for more balanced, hybrid approaches that can take on the research challenges outlined above. The insight, data, and models generated from the close collaboration of environmental historians, archeologists, ecologists, modelers, and many others will allow the construction and testing of new ideas about humans' relationship with the rest of nature. It will also allow the calibration and testing of a new generation of integrated global Earth system models that contain a range of embedded hypotheses about human-environment interactions.

We are poised to address a number of critical research and policy questions that affect the life of all humans on Earth. It is fitting at this point to conclude not with answers but with questions. The big, general questions for the IHOPE activity (consistent with the long-term goals stated earlier) can be summarized as the following:

What are the complex and interacting mechanisms and processes resulting in the emergence, sustainability, or collapse of socioecological systems?

What are the pathways to developing and evaluating alternative explanatory frameworks, specific explanations, and models (including complex systems models) by using observations of highly variable quality and coverage?

- How do we use knowledge of the integrated history of the Earth for understanding and creating the future?

It has been said that if one fails to understand the past, one is doomed to repeat it. IHOPE takes a much more "hopeful" and positive attitude. If we can really understand the past, we can create a better, more sustainable and desirable future.

\section{References and Notes}

1. Redman, C.L. 1999. Human Impact on Ancient Environments. University of Arizona Press, Tucson, AZ, 239 pp.

2. Steffen, W., Sanderson, A., Tyson, P. and Jäger, J. 2004. Global Change and the Earth System: A Planet Under Pressure. IGBP Global Change Series. Springer-Verlag, New York, $332 \mathrm{pp}$

3. Redman, C.L., James, S.R., Fish, P.R. and Rogers, J.D. 2004. The Archaeology of Global Change: The Impact of Humans on Their Environment. Smithsonian Books, Washington, DC, $240 \mathrm{pp}$.

4. Schellnhuber, H.J., Crutzen, P.J., Clark, W.C., Claussen, M. and Held, H. (eds). 2004. Earth System Analysis for Sustainability. Dahlem Workshop Report 91. MIT Press, Cambridge, MA, 468 pp.

Diamond, J. 2005. Collapse: How Societies Choose to Fail or Succeed. Viking, New York, $592 \mathrm{pp}$.

6. Kirch, P.V. 2005 Archeology and global change: the Holocene record. Annu. Rev. Environ. Resour. 30, 409.

7. Mann, C.C. 2005. 1491: New Revelations of the Americas before Columbus. Knopf, New York, $560 \mathrm{pp}$.

8. Crumley, C.L. (ed). 1994. Historical Ecology: Cultural Knowledge and Changing Landscapes. School of American Research, Santa Fe, NM, 304 pp

9. Costanza, R., Graumlich, L.J. and Steffen, W. (eds). 2007. Sustainability or Collapse? An Integrated History and Future of People on Earth. Dahlem Workshop Report 96. MIT Press. Cambridge, MA, $495 \mathrm{pp}$.

10. Hornborg, A. and Crumley, C. (eds). 2007. The World System and the Earth System: Global Socioenvironmental Change and Sustainability Since the Neolithic. Left Coast Press. Walnut Creek, CA, 395 pp.

11. Hornborg, A., McNeill, J.R. and Martinez-Alier, J. 2007. Rethinking Environmental History: World-System History and Global Environmental Change. Altamira Press, Lanham, MD, $384 \mathrm{pp}$.

12. A step toward the development of such an integrated history and future took place at a Dahlem conference in Berlin, Germany, June 2005. IHOPE-Dahlem assembled an interdisciplinary group of 40 top scholars from a range of natural and social science disciplines, with the goal of identifying mechanisms and generalizations of how humans have responded to and impacted their environment over millennial, centennial, and decadal time scales, as well as the future of the human-environment system. The IHOPE Dahlem Workshop was the kickoff event for a series of coordinated interdisciplinary research projects around the world that will help us better learn about the future from the past.

13. Grove, R. 2006. Revolutionary weather: the climatic and economic crisis of 1788-1795 and the discovery of El Niño. In: Sustainability or Collapse? An Integrated History and Future of People on Earth. Costanza, R., Graumlich, L.J. and Steffen, W. (eds). Dahlem Future of People on Earth. Costanza, R., Graumlich, L.J. and Steffen,
Workshop Report 96. MIT Press, Cambridge, MA, pp. 151-168.

14. Christian, D. 2004. Maps of Time: An Introduction to Big History. University of California Press, Berkley, CA, 664 pp.

15. Hibbard, K.A., Crutzen, P., Lambin, E.F., Liverman, D., Mantua, N.J., McNeill, J.R., Messerli, B. and Steffen, W. 2007. The Great Acceleration. In: Sustainability or Collapse? An Integrated History and Future of People on Earth. Costanza, R., Graumlich, L.J. and Steffen, W. (eds). Dahlem Workshop Report 96. MIT Press, Cambridge, MA, pp. 341-378.

16. Tainter, J.A. 1988. The Collapse of Complex Societies. Cambridge University Press, Cambridge, MA, $260 \mathrm{pp}$.

17. Yoffee, N. and Cowgill, G.L. (eds). 1988. The Collapse of Ancient States and Yoffee, N. and Cowgill, G.L. (eds). 1988. The Collapse
Civilizations. University of Arizona Press, Tucson, AZ, 348 pp.

18. Ponting, C. 1991. A Green History of the World: The Environment and the Collapse of Great Civilizations. Sinclair-Stevenson, London, UK, 464 pp.

19. Ostrom, E. 1998. A behavioral approach to the rational choice theory of collective action. Am. Pol. Sci. Rev. 92, 1-22.

20. Berkes, F., Colding, J. and Folke, C. (eds). 2002. Navigating Social-Ecological Systems: Building Resilience for Complexity and Change. Cambridge University Press, Cambridge, MA, $400 \mathrm{pp}$.

21. Costanza, R. and Voinov, A. (eds). 2003. Landscape Simulation Modeling: A Spatially Explicit, Dynamic Approach. Springer, New York, 330 pp.

22. Costanza, R., Leemans, R., Boumans, R. and Gaddis, E. 2007. Integrated global models. In: Sustainability or Collapse? An Integrated History and Future of People on Earth. Costanza, R., Graumlich, L.J. and Steffen, W. (eds). Dahlem Workshop Report 96. MIT Press, Cambridge, MA, pp. 417-446.

23. Young, M.N., Leemans, R., Boumans, R., Costanza, R., de Vries, B.J.M., Finnigan, J., Svedin, U. and Young, M.D. 2007. Future scenarios of human-environment systems. In: Sustainability or Collapse? An Integrated History and Future of People on Earth. Costanza, R., Graumlich, L.J. and Steffen, W. (eds). Dahlem Workshop Report 96. MIT Press, Cambridge, MA, pp. 447-470.

24. Turchin, P. 2003. Historical Dynamics: Why States Rise and Fall. Princeton University Press, Princeton, NJ, $264 \mathrm{pp}$.

25. Axtell, R.L., Epstein, J.M., Dean, J.S., Gumerman, G.J., Swedlund, A.C., Harburger, J., Chakrayarty, S., Hammond, R., et al. 2002. Population growth and collapse in a multiagent model of the Kayenta Anasazi in Long House Valley. Proc. Natl. Acad. Sci. 99, 7275-7279. 
26. Dearing, J., Battarbee, R.W., Dikau, R., Larocque, I. and Oldfield, F. 2006. Humanenvironment interactions: towards synthesis and simulation. Reg. Environ. Change. 6 , $115-123$.

27. Costanza, R. 2007 Assessing and communicating data quality: toward a system of data quality grading. In: Sustainability or Collapse? An Integrated History and Future of Cam Workshop Report 96. MIT Press, Cambridge, MA, pp. 39-50.

28. Dearing, J 2007. Human-environment interactions: learning from the past. In: Sustainability or Collapse? An Integrated History and Future of People on Earth Costanza, R., Graumlich, L.J. and Steffen, W. (eds). Dahlem Workshop Report 96. MIT Press, Cambridge, MA, pp. 19-38.

29. We thank H.J. Schellnhuber and Julia Lupp for their support and guidance in producing this paper and the Dahlem conference report on which it is based. We also thank the other participants in the Dahlem conference in June 2005 and a follow-up meeting in Stockholm in January 2006 for their valuable contributions: Steve Aulenbach, Roelo Boumans, Paul J. Crutzen, Bert J.M. de Vries, Carl Folke, John Finnigan, Richard Grove, Arnulf Grübler, Helmut Haberl, Fekri Hassan, Frank Hole, Eric F. Lambin, Diana Liverman, Nathan J. Mantua, John R. McNeill, Dennis Meadows, Bruno Messerli, João Morais, Dennis Ojima, Christian Pfister, Frank Riedel, Jim Reichman, Vernon L. Scarborough, Joseph A. Tainter, Peter Turchin, Sander van der Leeuw, Yoshinori Yasuda, Uno Svedin, Marianne N. Young and Michael D. Young. Many of earlier draft.

30. First submitted 23 October 2006. Accepted for publication 25 April 2007.
Robert Costanza is Gordon and Lulie Gund Professor of Ecological Economics and Director, Gund Institute for Ecological Economics. His address: Gund Institute for Ecological Economics, Rubenstein School of Environment and Natural Resources, The University of Vermont, Burlington, VT 05405, USA.

E-mail: Robert.Costanza@uvm.edu

Lisa J. Graumlich is Professor and Director, School of Natural Resources, The University of Arizona. Her address: School of Natural Resources, The University of Arizona, 325 Bioscience East, Tucson, AZ 85721, USA.

E-mail: lisag@cals.arizona.edu

Will Steffen is Professor Director, CRES and ANU Institute for Environment. His address: Centre for Resource and Environmental Studies (CRES), Australian National University, Canberra, ACT 0200, Australia.

E-mail: will.steffen@anu.edu.au

Carole Crumley is Professor and Director of Undergraduate Studies, Department of Anthropology, University of North Carolina. Her address: Department of Anthropology, University of North Carolina, Chapel Hill, NC 27599, USA.

E-mail: crumley@unc.edu

John Dearing is Chair, IGBP-PAGES Focus 5 Programme, and Professor, Department of Geography, University of Liverpool. His address: Department of Geography, University of Liverpool,
Liverpool, L69 7ZT, UK.

E-mail: j.dearing@liverpool.ac.uk

Kathy A. Hibbard is IGBP/AIMES Executive Officer and Project Scientist II, Climate and Global Dynamics Division, National Center for Atmospheric Research. Her address: Climate and Global Dynamics Division, National Center for Atmospheric Research, Boulder, CO 80307, USA.

E-mail: kathyh@ucar.edu

Rik Leemans is Professor, Environmental Systems Analysis Group, Department of Environmental Sciences, Wageningen University. His address: Department of Environmental Sciences, Wageningen University, 6700 AA Wageningen, The Netherlands. E-mail: rik.leemans@wur.nl

Charles L. Redman is Virginia M. Ullman Professor of Natural History and the Environment, and Julie Ann Wrigley Director, Global Institute of Sustainability, Arizona State University. His address: Global Institute of Sustainability, Arizona State University, Tempe, AZ 85287-3211, USA.

E-mail: CHARLES.REDMAN@asu.edu

David Schimel is Senior Scientist, Terrestrial Sciences Section, National Center for Atmospheric Research. His address: Terrestrial Sciences Section, National Center for Atmospheric Research, Boulder, CO 80305, USA.

E-mail: schimel@ucar.edu

\section{Erratum}

In "Managing Scuba Divers to Meet Ecological Goals for Coral Reef Conservation" by Michael G. Sorice, Chi-Ok Oh and Robert B. Ditton, Ambio 36, 316-322, the fifth paragraph of the Introduction should read:

Despite this, negative impacts on coral reefs from diving continue, because resource managers lack a thorough understanding of users, their willingness to play a greater role in coral conservation, and an effective means for dealing with their impacts. 